\title{
Under the Magnifying Glass: Searching for The Evidence of Pemetrexed in Nonsquamous Nonsmall Cell Lung Cancer
}

\author{
Sindhura Chitikela ${ }^{1}$ Neha Pathak ${ }^{1}$ Prabhat S. Malik ${ }^{10}$
}

${ }^{1}$ Department of Medical Oncology, Dr. Bhimrao Ramji Ambedkar Institute Rotary Cancer Hospital, All India Institute of Medical Sciences, New Delhi, India

Ind J Med Paediatr Oncol 2021;42:579-581.
Address for correspondence Prabhat S. Malik, MD, DM, Department of Medical Oncology, Room no. 245, Dr. Bhimrao Ramji Ambedkar Institute Rotary Cancer Hospital, All India Institute of Medical Sciences, New Delhi 110029, India (e-mail: drprabhatsm@gmail.com).
Platinum-based doublet chemotherapy has been the backbone of the treatment of advanced nonsmall cell lung cancer (NSCLC) before the advent of targeted therapy and immune checkpoint inhibitors. For patients without targetable mutations and ineligible or unaffordable for immunotherapy, chemotherapy remains the treatment of choice. ${ }^{1,2}$ Histology-based selection of chemotherapy brought pemetrexedplatinum combination for nonsquamous subtype to the center stage; however, this paradigm shift was based only on a subgroup analysis of a phase- 3 randomized trial with noninferiority design. ${ }^{3}$ Subsequent trials, PRONOUNCE and point break restricted to nonsquamous histology only, could not demonstrate clear superiority of pemetrexed based combination; however, the addition of bevacizumab in one or both treatment arms might have influenced the results., ${ }^{4,5}$

Point beak trial compared pemetrexed-carboplatin-bevacizumab and paclitaxel-carboplatin-bevacizumab with progression-free survival (PFS), significantly better in the pemetrexed arm with similar overall survival (OS). ${ }^{4}$ PRONOUNCE trial demonstrated that pemetrexed-carboplatin resulted in numerically improved PFS; however, it was not superior to paclitaxel carboplatin bevacizumab in terms of PFS and OS which might have been masked by the effect of bevacizumab in comparator arm. $^{5}$ Use of bevacizumab in first-line advanced NSCLC has shown PFS and OS benefit when combined with taxane and nontaxane based regimens. ${ }^{6-9}$

Ease of administration and better nonhematological safety profile are certainly a few advantages of pemetrexedplatinum combination over other regimens; however, cost issues remain a concern. The superiority of pemetrexed- platinum was never demonstrated in patients with advanced nonsquamous NSCLC in chemotherapy alone comparisons.

Recently, we have published the results of a randomized control trial comparing pemetrexed-carboplatin with paclitaxel (weekly)-carboplatin in advanced nonsquamous NSCLC in the June 2021 issue of Oncology. ${ }^{10}$

This was a single-center, open-labeled randomized trial. It was powered to detect superiority of pemetrexed-carboplatin over paclitaxel-carboplatin by $15 \%$ in terms of 6 -month PFS rates (primary outcome) and a total of 182 events were required for the same. Patients with known driver mutation positive status were excluded; however, we included the patients in whom the mutation results were awaited. Paclitaxel was given in a weekly manner due to the inclusion of patients with the Eastern Cooperative Oncology Group Performance status (ECOG PS) $2 .^{11}$ Patients aged 18 to 65 years with ECOG PS 0 to 2 were randomized into one of the study arms, experimental arm, pemetrexed $500 \mathrm{mg} / \mathrm{m}^{2}$ and carboplatin area under curve (AUC) of 5 every 3 weeks for four cycles, or control arm, paclitaxel $80 \mathrm{mg} / \mathrm{m}^{2}$ on days 1,8 , and 15 with carboplatin AUC of 5 on day 1 at every 4 weeks for four cycles. Responding patients in both arms were allowed to receive maintenance pemetrexed $500 \mathrm{mg} / \mathrm{m}^{2}$ every 3 weekly until disease progression or intolerance. The primary endpoint was 6-month PFS rate and secondary endpoints were objective response rates, disease control rates, overall OS, and toxicities.

This study was terminated early because of slow accrual and change in the standard of care for advanced NSCLC during the trial period; however, almost $76 \%$ of the required
DOI https://doi.org/ 10.1055/s-0041-1735516. ISSN 0971-5851. (c) 2021. Indian Society of Medical and Paediatric Oncology. All rights reserved.

This is an open access article published by Thieme under the terms of the Creative Commons Attribution-NonDerivative-NonCommercial-License, permitting copying and reproduction so long as the original work is given appropriate credit. Contents may not be used for commercial purposes, or adapted, remixed, transformed or built upon. (https://creativecommons.org/ licenses/by-nc-nd/4.0/)

Thieme Medical and Scientific Publishers Pvt. Ltd., A-12, 2nd Floor, Sector 2, Noida-201301 UP, India 
events had already occurred at the time of data analysis. Between April 2016 and January 2019, a total of 171 patients were randomized. Finally, 83 patients in the pemetrexed arm and 81 in the paclitaxel arm were included in the analysis. Baseline characteristics were well matched among both the study arms including the number of patients subsequently detected to have driver mutations. ECOG PS 2 constituted up to $28 \%$ and $26 \%$ in pemetrexed and paclitaxel arms, respectively. Brain metastases were present in $19.28 \%$ and $19.75 \%$ of patients in each treatment arm, respectively.

After a median follow-up of 17 months, 6-month PFS rates were $47.45 \%$ and $48.64 \%$ in pemetrexed and paclitaxel arms, respectively $(p=0.88)$. Median PFS was 5.67 months (95\% confidence interval $[\mathrm{CI}]: 3.73-7.3)$ in the pemetrexed arm and 5.03 months (95\% CI: 2.63-7.43) in the paclitaxel arm (hazard ratio $[\mathrm{HR}]=1.13 ; 95 \% \mathrm{CI}: 0.81-1.59 ; p=0.44$ ). Objective response rates were significantly higher in the paclitaxel group ( $30 \%$ vs. $15.79 \% ; p=0.04$ ); however, clinical benefit rates (complete response + partial response + stable disease) were similar in both treatment groups $(58.7 \%$ vs. $60.53 \%$; $p=0.81$ ). Median OS in the pemetrexed arm was 14.83 months (95\% CI: 9.5-18.73), while 11.3 months (95\% CI: 8.3-19.7) in the paclitaxel arm. The difference was not statistically significant $(\mathrm{HR}=1.19,95 \% \mathrm{CI}$ : $0.8-1.78 ; p=0.37)$. Four cycles of chemotherapy could be completed in $61 \%$ of patients in the pemetrexed arm and 52\% in the paclitaxel arm. The most common reason for discontinuation of chemotherapy was progressive disease. Both the chemotherapy regimens were well tolerated. Toxicity profile was not much different, except for alopecia and peripheral neuropathy, as expected, which were higher in the paclitaxel arm.

Overall, this study failed to demonstrate the superiority of pemetrexed-carboplatin combination over paclitaxel (weekly)-carboplatin in advanced nonsquamous NSCLC and thus, further challenges the current practice change which was based solely on a subgroup analysis of a noninferiority study. Although this study was terminated early, at 75\% maturity in terms of the number of events, there was no difference in PFS. It was highly unlikely to detect a difference even if the study would have completed its planned sample size. This study is particularly relevant in the Indian context, since a large majority of patients are still treated primarily with chemotherapy, owing to drug availability issues and cost constraints. The incorporation of patients with ECOG PS 2 (almost one-fourth of total patients) in this study correlates well with the real-world scenario, especially in developing countries such as India. Interestingly, higher objective response rates were seen with paclitaxel (weekly)-carboplatin combination, making it a suitable regimen for patients with heavy disease burden. Belani et al have also shown better objective response rates with weekly paclitaxel over standard 3 weekly paclitaxel based regimen, and similar to our study, no difference in survival outcomes. ${ }^{11}$ Weekly paclitaxel regimen has been preferred particularly for the elderly population. ${ }^{12}$ Major studies comparing pemetrexedplatinum combination with other regimens are summarized in - Table 1. Quality of life assessment and cost-effectiveness analysis would have added to the relevance of this study.

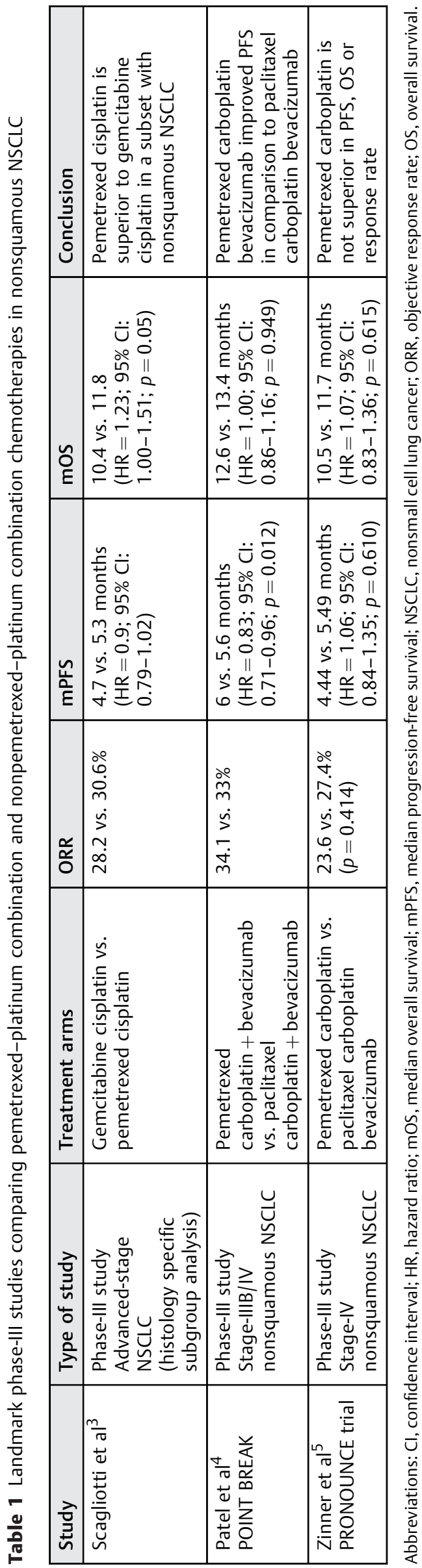


Selection of a chemotherapy regimen should be based on the patient's clinical profile, disease burden, and acceptable toxicity pattern.

\section{Conflict of Interest \\ None declared.}

\section{References}

1 Ettinger DS, Wood DE, Aisner DL, et al. NCCN guidelines insights: non-small cell lung cancer, version 2.2021. J Natl Compr Canc Netw 2021;19(03):254-266

2 Clinical practice living guidelines - metastatic non-small-cell lung cancer. Accessed June 2, 2021 at: https://www.esmo.org/guidelines/lung-and-chest-tumours/clinical-practice-livingguidelines-metastatic-non-small-cell-lung-cancer

3 Scagliotti GV, Parikh P, von Pawel J, et al. Phase III study comparing cisplatin plus gemcitabine with cisplatin plus pemetrexed in chemotherapy-naive patients with advanced-stage non-smallcell lung cancer. J Clin Oncol 2008;26(21):3543-3551

4 Patel JD, Socinski MA, Garon EB, et al. PointBreak: a randomized phase III study of pemetrexed plus carboplatin and bevacizumab followed by maintenance pemetrexed and bevacizumab versus paclitaxel plus carboplatin and bevacizumab followed by maintenance bevacizumab in patients with stage IIIB or IV nonsquamous non-small-cell lung cancer. J Clin Oncol 2013;31(34): 4349-4357

5 Zinner RG, Obasaju CK, Spigel DR, et al. PRONOUNCE: randomized, open-label, phase III study of first-line pemetrexed + carboplatin followed by maintenance pemetrexed versus paclitaxel + carboplatin + bevacizumab followed by maintenance bevacizumab in patients ith advanced nonsquamous non-small-cell lung cancer. J Thorac Oncol 2015;10(01):134-142
6 Niho S, Kunitoh H, Nokihara H, et al; J019907 Study Group. Randomized phase II study of first-line carboplatin-paclitaxel with or without bevacizumab in Japanese patients with advanced non-squamous non-small-cell lung cancer. Lung Cancer 2012;76 (03):362-367

7 Johnson DH, Fehrenbacher L, Novotny WF, et al. Randomized phase II trial comparing bevacizumab plus carboplatin and paclitaxel with carboplatin and paclitaxel alone in previously untreated locally advanced or metastatic non-small-cell lung cancer. J Clin Oncol 2004;22(11):2184-2191

8 Zhou C, Wu Y-L, Chen G, et al. BEYOND: a randomized, doubleblind, placebo-controlled, multicenter, phase iii study of firstline carboplatin/paclitaxel plus bevacizumab or placebo in chinese patients with advanced or recurrent nonsquamous non-small-cell lung cancer. J Clin Oncol 2015;33(19): 2197-2204

9 Sandler A, Gray R, Perry MC, et al. Paclitaxel-carboplatin alone or with bevacizumab for non-small-cell lung cancer. N Engl J Med 2006;355(24):2542-2550

10 Yadav A, Malik PS, Khurana S, et al. An open-label randomized controlled trial comparing the efficacy and safety of pemetrexedcarboplatin versus (weekly) paclitaxel-carboplatin as first-line chemotherapy in advanced non-squamous non-small cell lung cancer. Oncology 2021;99(06):389-396

11 Belani CP, Ramalingam S, Perry MC, et al. Randomized, phase III study of weekly paclitaxel in combination with carboplatin versus standard every-3-weeks administration of carboplatin and paclitaxel for patients with previously untreated advanced non-smallcell lung cancer. J Clin Oncol 2008;26(03):468-473

12 Ramalingam S, Perry MC, La Rocca RV, et al. Comparison of outcomes for elderly patients treated with weekly paclitaxel in combination with carboplatin versus the standard 3-weekly paclitaxel and carboplatin for advanced nonsmall cell lung cancer. Cancer 2008;113(03):542-546 